\title{
The role of chemerin and ChemR23 in stimulating the invasion of squamous oesophageal cancer cells
}

\author{
J Dinesh Kumar ${ }^{1}$, Sandhir Kandola ${ }^{1}$, Laszlo Tiszlavicz² ${ }^{2}$ Zita Reisz ${ }^{2}$, Graham J Dockray ${ }^{1}$ and Andrea Varro ${ }^{*}, 1$ \\ ${ }^{1}$ Department of Cellular and Molecular Physiology, Institute of Translational Medicine, University of Liverpool, Liverpool, UK and \\ ${ }^{2}$ Department of Pathology, University of Szeged, Szeged, Hungary
}

Background: Stromal cells, including cancer-associated myofibroblasts (CAMs), are recognised to be determinants of cancer progression, but the mechanisms remain uncertain. The chemokine-like protein, chemerin, is upregulated in oesophageal squamous cancer (OSC) CAMs compared with adjacent tissue myofibroblasts (ATMs). In this study, we hypothesised that chemerin stimulates OSC cell invasion.

Methods: Expression of the chemerin receptor, ChemR23, in OSC was examined by immunohistochemistry. The invasion of OSC cells was studied using Boyden chambers and organotypic assays, and the role of chemerin was explored using siRNA, immunoneutralisation and a ChemR23 receptor antagonist. Matrix metalloproteinases (MMPs) were detected by western blot, enzyme assays or immunohistochemistry.

Results: Immunohistochemistry indicated expression of the putative chemerin receptor ChemR23 in OSC. It was also expressed in the OSC cell line, OE21. Chemerin stimulated OE21 cell migration and invasion in Boyden chambers. Conditioned medium (CM) from OSC CAMs also stimulated OE21 cell invasion and this was inhibited by chemerin immunoneutralisation, the ChemR23 antagonist CCX832, and by pretreatment of CAMs with chemerin siRNA. In organotypic cultures of OE21 cells on Matrigel seeded with either CAMs or ATMs, there was increased OE21 cell invasion by CAMs that was again inhibited by CCX832. Chemerin increased MMP-1, MMP-2 and MMP-3 abundance, and activity in OE21 cell media, and this was decreased by inhibiting protein kinase $\mathrm{C}$ and $\mathrm{p} 44 / 42$ MAPK kinase but not PI-3 kinase.

Conclusions: The data indicate that OSC myofibroblasts release chemerin that stimulates OSC cell invasion. Treatments directed at inhibiting chemerin-ChemR23 interactions might be therapeutically useful in delaying progression in OSC.

The role of stromal cells in promoting tumour growth is well recognised (Hanahan and Weinberg, 2011; Quail and Joyce, 2013). In addition to inflammatory and immune cells (Wang and DuBois, 2015), there has been increasing recognition of the role of cells of fibroblastic lineages (Orimo et al, 2005; De Wever et al, 2008). The heterogeneity of the latter and in particular differences between cancer-associated fibroblasts (CAFs) and normal tissue fibroblasts has attracted increasing interest (Jiang et al, 2008; Ohlund et al, 2014). Cancer-associated myofibroblasts (CAMs) are an important subgroup of CAFs, and have been shown to differ from both normal tissue myofibroblasts (NTMs) and tumour adjacent tissue myofibroblasts (ATMs), notably promoting a more aggressive cancer cell phenotype both in vivo in xenografts and in vitro in proliferation, migration and invasion assays (De Wever et al, 2008; De Wever et al, 2014). These differences may be attributable to decreased production of tumour inhibitory factors (Holmberg et al, 2012a), increased expression and activation of matrix metalloproteinases (MMPs; Holmberg et al, 2013) and increased production of growth factors and chemokines (Orimo et al, 2005).

*Correspondence: Professor A Varro; E-mail: avarro@liverpool.ac.uk

Received 16 December 2015; revised 7 March 2016; accepted 11 March 2016; published online 19 April 2016

(c) 2016 Cancer Research UK. All rights reserved 0007-0920/16 
Cancers of the oesophagus account for approximately half a million deaths worldwide per annum and are the sixth commonest cause of mortality due to cancer (Jemal et al, 2011). Adenocarcinoma of the oesophagus is increasing in incidence and is particularly common in white males; it is associated with the preneoplastic condition of Barrett's metaplasia of the oesophagus that arises following chronic reflux of bile salts and gastric acid (Reid et al, 2010; Pennathur et al, 2013). In contrast, squamous cancer of the oesophagus (OSC) is particularly common in South East Asia. There is an association between OSC and smoking, alcohol and poor diet. In both cancers, the outlook after diagnosis is poor. Epithelial-stromal interactions in oesophageal cancer have been recognised but are not well studied (Grugan et al, 2010).

The chemokine-like peptide chemerin is expressed in a variety of cell types and has a role in the recruitment of NK and dendritic cells via activation of the G-protein-coupled receptor, ChemR23 (chemokine-like receptor-1) (Meder et al, 2003; Wittamer et al, 2003). We recently reported increased expression of chemerin in OSC CAMs compared with paired ATMs and demonstrated roles in the recruitment of mesenchymal stromal cells (MSCs) and in their regulated secretion (Kumar et al, 2014; Kumar et al, 2015a). In addition, increased chemerin expression has been identified in oesophageal adenocarcinoma compared with adjacent Barrett's tissue (Somja et al, 2013). In the present study, we hypothesised that chemerin might also have a role within the oesophageal tumour microenvironment by acting on cancer cells. We report here the expression of ChemR23 in OSC, and show that chemerin stimulates OSC cell invasion.

\section{MATERIALS AND METHODS}

Cells. Myofibroblasts generated from tumours and adjacent tissue of patients with OSC, or from normal oesophagus of transplant donors, were used as previously described (Balabanova et al, 2014; Kumar et al, 2014). The OSC cell line, OE21, was obtained from American Type Culture Collection (Manassas, VA, USA). Myofibroblasts and OE21 cells were maintained as previously described (Kumar et al, 2014).

Patients. Primary tissue was obtained from 13 patients with OSC (12 male; age, $64.7 \pm 2.7$ years, range $56-85$ ). No patient had distant metastases; most patients had low lymph node involvement (pN0, $n=6 ;$ pN1 $n=5 ; \mathrm{pN} 2, n=2$ ) and most had invasive tumours (pT1, $n=3 ;$ pT2, $n=3 ;$ pT3, $n=7$ ). Tumour and adjacent tissue were fixed in $10 \%$ neutral-buffered formalin for paraffin embedding. All patients gave informed consent and the study was approved by the University of Szeged ethics committee.

Immunohistochemistry. Tissue sections were processed for immunohistochemical detection of ChemR23 using rabbit polyclonal antibody (Novus Biologicals, Littleton, CO, UAS); for comparison, adjacent sections were processed for MMP-1 using mouse monoclonal antibody, MMP-2 using goat polyclonal antibody (R\&D Systems, Minneapolis, MN, USA) and MMP-3 using rabbit monoclonal antibody (Abcam, Cambridge, UK). En Vision FLEX/HRP (Dako, Carpinteria, CA, USA) was used for secondary antibody. Antigen retrieval was performed by incubating at $\mathrm{pH} 9.0,93^{\circ} \mathrm{C}$, for $15 \mathrm{~min}$ as previously described (Kumar et al, $2015 b)$. Organotypic cultures were processed for immunohistochemistry using the same method and antibodies to MMP-1, MMP-2 and MMP-3, followed by En Vision FLEX/HRP (Dako) visualisation. Cultured cells were processed for immunocytochemistry after fixation with paraformaldehyde (4\% w/v). They were permeabilised with $0.2 \%$ Triton X-100 and processed using primary antibody to ChemR23 (Novus Biologicals) or GPR1 (Abcam), followed by incubation with the appropriate fluorescein-labelled secondary antibody raised in donkey (Jackson
Immunoresearch, Soham, UK) and mounted with Vectashield containing DAPI (Vector Laboratories, Peterborough, UK) as previously described (Kumar et al, 2014). Slides were viewed using a Zeiss Axioplan-2 microscope (Zeiss Vision, Welwyn Garden City, $\mathrm{UK}$ ) and images were captured using a JVC-3 (Yokohama-shi, Kanagawa, Japan) charge-coupled device camera at $\times 40$ magnification as previously described (Kumar et al, 2014).

Conditioned media. Myofibroblasts $\left(1.5 \times 10^{6}\right.$ cells $)$ were plated in T-75 falcon flasks and maintained at $37^{\circ} \mathrm{C}$ in $5 \% \mathrm{v} / \mathrm{v} \mathrm{CO}_{2}$ for $24 \mathrm{~h}$ in full media (FM). Cultures were then washed three times and incubated in $15 \mathrm{ml}$ serum-free media for $24 \mathrm{~h}$. CM was collected, centrifuged $\left(7 \mathrm{~min}, 800 \mathrm{~g}, 4^{\circ} \mathrm{C}\right.$ ) and aliquots were stored at $-80^{\circ} \mathrm{C}$ until further use as previously described (Kumar et al, 2014).

Cell migration and invasion assays. Transwell migration assays and invasion assays were performed using $8-\mu \mathrm{m}$ pore size $\mathrm{BD}$ inserts and $\mathrm{BD}$ BioCoat Matrigel invasion chambers respectively (BD Bioscience, Franklin Lakes, NJ, USA) as previous described (Holmberg et al, 2012b) employing chemerin (R\&D Systems) or undiluted $\mathrm{CM}$ in the lower well. The effects of chemerinneutralising antibody (MAb2325, R\&D Systems) and the ChemR23 antagonist CCX832 or its inactive enantiomer, CCX826 (generous gifts of ChemoCentryx, Mountain View, CA, USA), were studied. Migrated cells were fixed, stained and quantified for a total of five fields per membrane, and experiments were performed in triplicate. Scratch-wound migration assays were performed as previously described (Kumar et al, 2014).

Proliferation assays. Proliferation of OE21 cells with or without chemerin was assessed by incorporation of $\operatorname{EdU}(10 \mu \mathrm{M})$ using the Click-iT EdU Alexa Fluor 488 Imaging kit (Invitrogen, Paisley, UK) as described previously (Holmberg et al, 2012a) and by measurement of colony formation units (CFUs). In the latter, 500 cells per well were seeded in six-well plates and incubated in FM for $24 \mathrm{~h}$. After the cells attached, fresh media was added to the well and incubated for 8-10 days as appropriate to reach the threshold colony size $(\geqslant 50$ cells). Media was changed once on the fourth day. After incubation, cells were washed and stained with clonogenic reagent containing $50 \%$ ethanol and $0.25 \% 1,9-$ dimethyl-methylane blue. Experiments were performed in triplicates.

Chemerin and ChemR23 knockdown. Myofibroblasts were transfected using Amaxa Fibroblast Nucleofector kits (Amaxa, Köln, Germany) with scrambled controls (Sigma-Aldrich, Dorset, UK) or previously validated silencing RNAs (siRNA) for chemerin, or ChemR23, using nucleofection as previously described (Kumar et al, 2014). The efficiency of chemerin knockdown had previously been established by western blotting and was further demonstrated in this study using ELISA (Kumar et al, 2014). The efficiency of ChemR23 knockdown was demonstrated by immunohistochemistry (see above) using GPR1 as a negative control.

Organotypic culture. Organotypic cultures were grown as described previously (Smola et al, 1993; Nystrom et al, 2005). In brief, OE21 cells $\left(1-10^{6}\right)$ were seeded on top of $1: 1$ Matrigel (Corning, Tewksbury, MA, USA)/collagen-I (Millipore, Watford, Hertfordshire, UK) with or without myofibroblasts $\left(0.5 \times 10^{6}\right)$ suspended in the gel. On day 3 , the culture was raised on wire gauze and maintained at an air medium interface for 21 days, changing medium every $48 \mathrm{~h}$. Cultures were fixed in $10 \%$ neutralbuffered formalin and paraffin-embedded sections were stained with haematoxylin and eosin. Invasion was determined by measuring the depth of invading cancer cells into the Matrigel. A total of eight measurements were taken per field and eight fields were captured per treatment at $\times 10$ magnification. Experiments were performed in triplicate. 
Gel contraction. Gel contraction assays were performed using myofibroblasts as described (Ngo et al, 2006). In brief, $500 \mu \mathrm{l}$ of collagen lattice was prepared by mixing two parts of cell suspension and eight parts of cold collagen gel solution (Millipore), at a final concentration of $1.5 \times 10^{5}$ cells per well in 24 -well plates. To initiate contraction, collagen gels were gently released from the sides of the culture dishes using a sterile spatula. Images of gels were taken with a Canon digital camera (Reigate, Surrey, UK) at multiple time points $(0,24,48$ and $72 \mathrm{~h})$. Gel contraction was calculated as a percentage of the initial area of the gel.

Western blotting. Media was concentrated using Strataclean resin (Agilent Technologies, Santa Clara, CA, USA; Holmberg et al, 2012a). Cell extracts were prepared in RIPA buffer containing protease and phosphatase inhibitors (Calbiochem, Darmstadt, Germany), resolved by SDS-PAGE electrophoresis and processed for western blotting, as previously described using antibodies to MMP-1, MMP-2, MMP-3 (R\&D Systems) and MMP-7 (Cambridge Research Biochemicals, Billingham, UK).

MMP activity assays. The activity of MMP-1, MMP-2/9 and MMP-3 in OE21 cell media was determined in response to chemerin for $24 \mathrm{~h}$ by a selective fluorescence substrate (Merk Biosciences, Beeston, UK) as previously described (Holmberg et al, 2013).

Statistics. The results are expressed as the mean \pm s.e.m. and comparisons were performed using Student's $t$-test or ANOVA as appropriate using Systat Software (Systat Software Inc., London, UK) unless otherwise stated.

\section{RESULTS}

ChemR23 expression in squamous oesophageal cancer. Immunohistochemical studies indicated the expression of ChemR23 in OSC cells. In normal oesophagus, there was some staining in the deeper layers of the squamous epithelium (Figure 1A). However, in dysplastic cells (Figure 1B) and in all of 13 tumours examined, there was strong expression (Figure 1C). Over 75\% of tumour cells were scored as staining at the highest intensity. In addition, there was staining of spindle-shaped stromal cells (Figure 1D). For comparison, we also examined the distribution of MMP-1 and MMP-3 in these tumours that showed strong expression in both cancer and stromal cells (Figure $1 \mathrm{E}$ and F).

OE21 cells express functional ChemR23. The OSC cell line, OE21, also expressed ChemR23 (Figure 2A). To validate the specificity of the antibody used in immunohistochemistry, we showed that knockdown of ChemR23 in OE21 cells using siRNA substantially and significantly reduced the number of cells exhibiting ChemR23 expression, whereas expression of GPR1, used as a negative control, was unaffected (Figure 2A). In functional assays, chemerin stimulated the migration of these cells in Boyden chamber and scratch-wound assays (Figure 2B and C). In addition, it increased OE21 cell growth measured in CFU or EdU incorporation assays (Figure 2D and E). The Chem23 receptor antagonist, CCX832, dose dependently reversed the action of chemerin (Figure 2F), whereas an inactive control compound, CCX826, did not (Figure 2G).

Chemerin released by myofibroblasts acts on OE21 cells. To determine whether chemerin released from myofibroblasts influenced OE21 cell function, we recovered CM from OSC CAMs and ATMs, and from oesophageal NTMs. In each case, CM stimulated migration of OE21 cells in Boyden chambers, but the response to CAM-CM was significantly greater than that to ATM-CM or NTM-CM (Figure 3A). Evidence to support a role for chemerin in mediating the effect of myofibroblast $\mathrm{CM}$ is provided by the observations that (a) siRNA inhibition of chemerin expression in CAMs, which reduced concentrations in media from 1.7 to $0.1 \mathrm{ng} \mathrm{ml}^{-1}$, also reduced the activity of CAM-CM in stimulating OE21 cell migration (Figure 3B); (b) immunoneutralising antibody to chemerin inhibited the effect of CAM-CM on OE21 cell migration (Figure 3C); (c) the ChemR23 antagonist CCX832 inhibited the OE21 cell migratory response to CAM-CM (Figure 3C).

Chemerin released by myofibroblasts stimulates OE21 cell invasion. We then asked whether chemerin has a part in myofibroblast stimulation of OSC cell invasion. Initially, using Matrigel-coated Boyden chambers, we found that OE21 cell
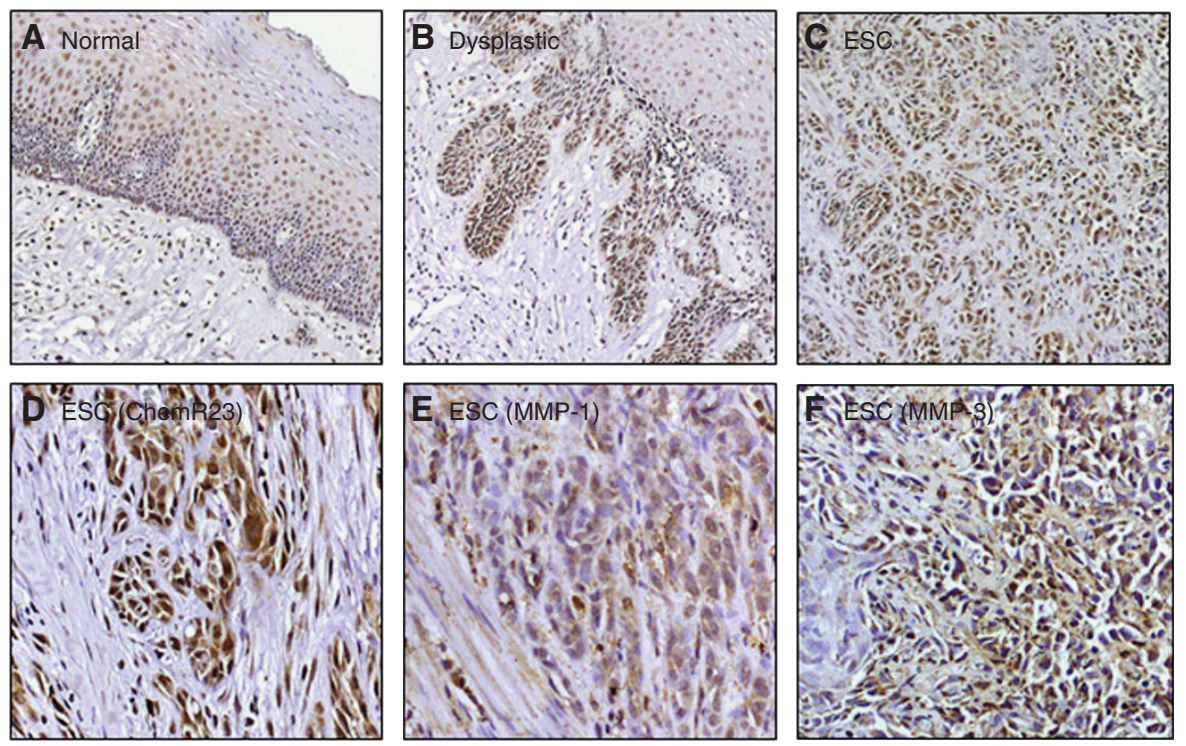

Figure 1. Immunohistochemical localisation of chemR23, MMP-1 and MMP-3 in oesophageal squamous cancer. (A) Staining for chemR23 in normal oesophagus. (B) Staining for chemR23 in dysplasia in the same patient. (C) Staining for chemR23 in cancer in the same patient. (D) ChemR23 expression in tumour cells at higher power. (E) Staining for MMP-1 in OSC. (F) Staining for MMP-3 in OSC. (A-C) $\times 10$ magnification. (D-F) $\times 20$ magnification. 
A

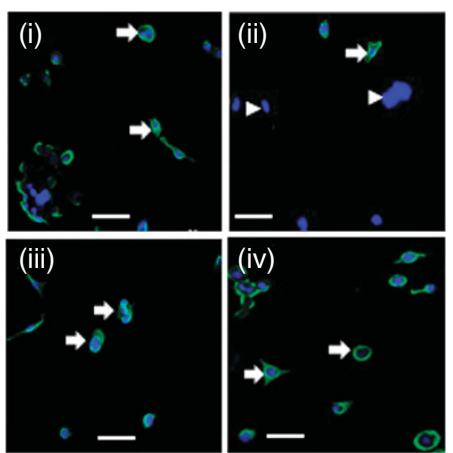

(v)

B

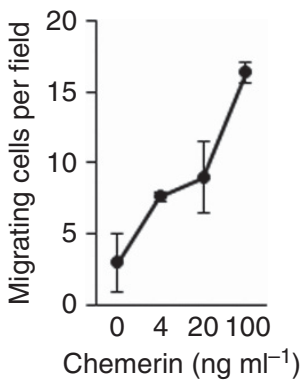

C

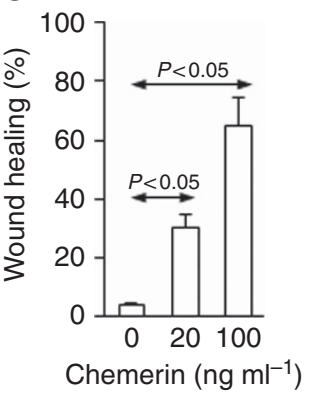

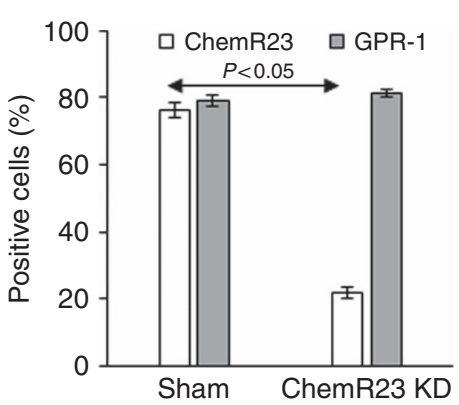

D

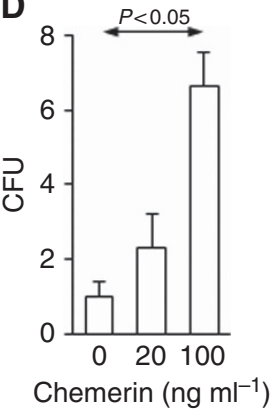

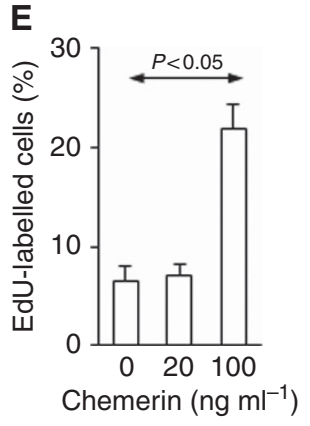

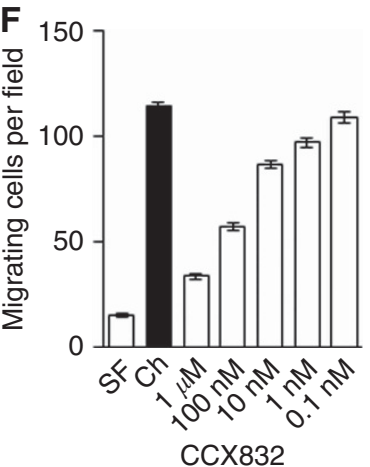

G

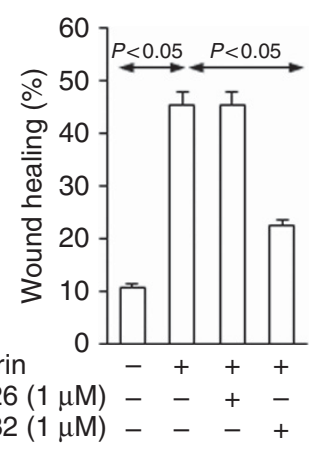

Figure 2. Chemerin stimulates migration and proliferation of OE21 cells via chemR23. (A) Immunocytochemical localisation of chemR23 in OE21 cells and validation by knockdown; (i) control, localisation of chemR23; filled arrows indicate examples of positively stained cells. (ii) Localisation of chemR23 after siRNA knockdown; note cells (arrowheads) indicated by DAPI-stained nuclei that do not express the receptor, as well as some that do (filled arrows). (iii) Localisation of a control G-protein-coupled receptor, GPR1. (iv) Knockdown of chemR23 does not affect the expression of GPR1 (filled arrows). Scale bar, $50 \mu \mathrm{m}$. (v) Quantification of positively stained cells after chemR23 knockdown: there is a significant reduction in chemR23 but not in GPRI used as a negative control. (B) Concentration-dependent stimulation of OE21 cell migration by chemerin in Boyden chamber migration assays. (C) Stimulation of OE21 cells by chemerin in scratch-wound migration assays. (D) Increased colony formation (CFU) in OE21 cells in response to chemerin. (E) Increased incorporation of EdU in OE21 cells in response to chemerin. (F) CCX832 dose dependently reversed the action of chemerin $(\mathrm{Ch})$ in Boyden chamber migration assays. (G) CCX832 inhibits chemerin-stimulated wound healing. Horizontal arrows, $P<0.05$, ANOVA.

invasion was stimulated by chemerin and this was inhibited by CCX832 but not CCX826 (Figure 4A). We then explored invasion in organotypic cultures in which the Matrigel/collagen gels were seeded with myofibroblasts and OE21 cells layered on the gel surface. There was marked invasion of the gel by OE21 cells after 7 days, which further increased at 14 and 21 days. The presence of myofibroblasts in the gel increased OE21 cell invasion, and CAMs were more active in this assay than ATMs or NTMs (Figure 4B and C). We considered the possibility that the differences between CAM, ATMs and NTMs might in some way be a consequence of different contractile effects on the gel layer. However, in gel contraction assays, there was no difference in activity between the three types of myofibroblast (Figure 4D). The invasion of OE21 cells in the absence of CAMs was not influenced by CCX832 (or the inactive compound CCX826). However, the invasion in the presence of CAMs was inhibited by CCX832, but not CCX826, pointing to a role for ChemR23 in mediating the invasive response (Figure $4 \mathrm{E}$ and $\mathrm{F}$ ).

Chemerin stimulates MMP expression. As invasion involves proteolytic digestion of extracellular matrix, we examined the expression of MMP-1, MMP-2 and MMP-3 in organotypic cultures. All three MMPs were expressed and could be found in both OE21 cells and myofibroblasts (Figure 5A). There was evidence of increased expression in OE21 cells in cultures that contained CAMs, as the number of fields exhibiting the most intense staining in OE21 cells was significantly higher in this case compared with OE21 cells alone (Figure 5B). Evidence that directly supports the action of chemerin on MMP expression by OE21 cells was provided by western blots, showing increased abundance of 
A

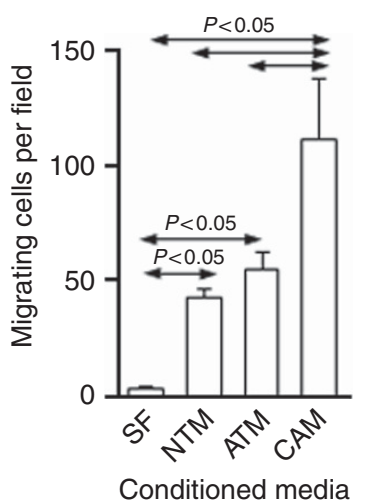

B

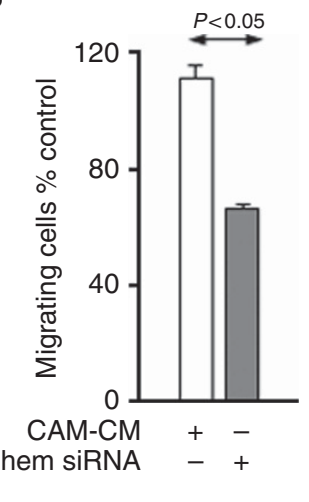

C

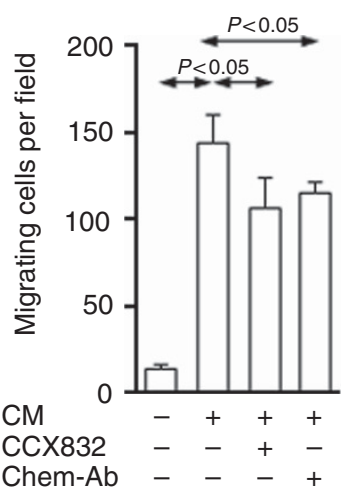

Figure 3. Stimulation of migration of OE21 cells by myofibroblast-derived chemerin. (A) Increased migration of OE21 in Boyden chambers in response to CAM-CM compared with ATM-CM and NTM-CM. (B) Stimulation of OE21 cell migration by CAM-CM was inhibited by conditioned media (CM) from CAMs transfected with chemerin siRNA. (C) Stimulation of OE21 cell migration by CAM-CM was inhibited by chemerinneutralising antibody (Chem-Ab, $10 \mu \mathrm{g} \mathrm{ml}^{-1}$ ) and by the chemerin receptor antagonist, CCX832; Horizontal arrows, $P<0.05$, ANOVA.

A

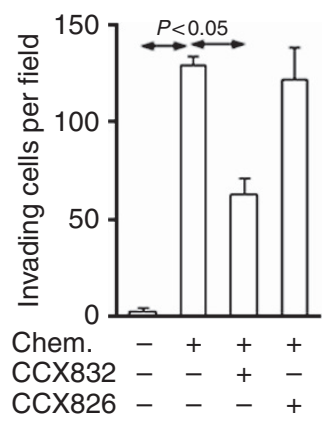

B

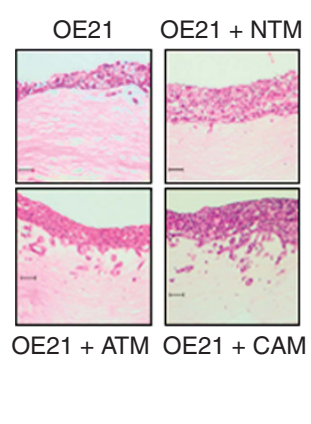

C

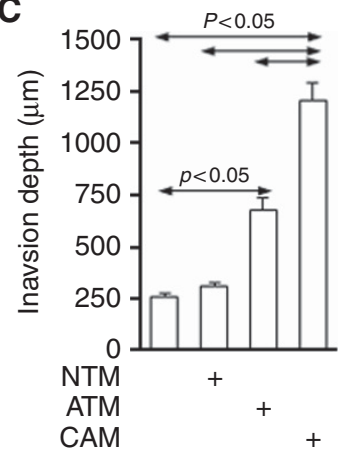

$\mathbf{F}$
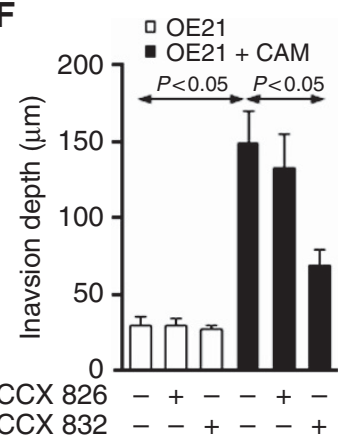

Figure 4. Chemerin increases the invasion of OE21 cells. (A) Chemerin stimulates invasion of OE21 cells in Matrigel-coated Boyden chambers and this is inhibited by the ChemR23 antagonist CCX832 but not the control compound CCX826. (B) Increased OE21 cell invasion in organotypic cocultures of cancer cells and CAMs compared with ATMs and NTMs. (C) The invasion depth of OE21 cells in organotypic co-cultures of OE21 cells and CAMs. (D) Quantification of the gel contraction assays of collagen with CAMs, ATMs and NTMs. (E) Representative images of organotypic cocultures of OE21 cells and CAMs treated with CXCR832 and its inactive analogue CXCR826. (F) The invasion depth of OE21 cells in response to treatment of organotypic cultures with CXCR832. Note invasion is only inhibited when OE21 cells are co-cultured with CAMs. Horizontal arrows, $P<0.05$, ANOVA.

bands stained with antibodies to MMP-1, MMP-2 and MMP-3 (Figure 5C). As a negative control, MMP-7 (which is poorly expressed by OE21 cells) exhibited no detectable bands. The main bands of MMP-1, MMP-2 and MMP-3 corresponded to the enzyme precursors; however, there were minor bands corresponding to the active species. The effect of chemerin on MMP-1, MMP2 and MMP-3 expression was mediated by protein kinase C (PKC), as the protein kinase inhibitor, Ro31822, fully inhibited MMP responses. An inhibitor of MAP kinase activation also reduced chemerin-induced MMP expression, whereas a PI-3 kinase inhibitor had no effect (Figure 5D). In addition, enzyme activity assays revealed that chemerin significantly increased the activity of MMP-1, MMP-2 and MMP-3 in OE21 cell media (Figure 5E).

\section{DISCUSSION}

Squamous oesophageal cancer myofibroblasts exhibit increased expression of the chemokine-like peptide, chemerin (Kumar et al, 2014). The present study shows that the putative receptor, 
A

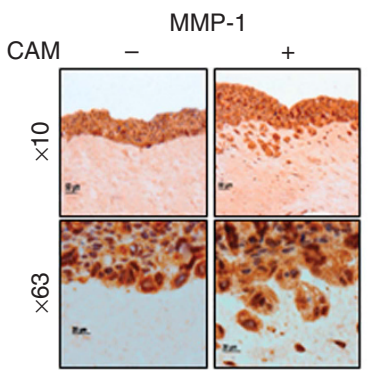

B

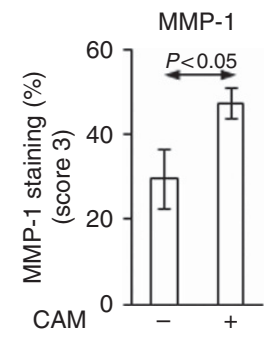

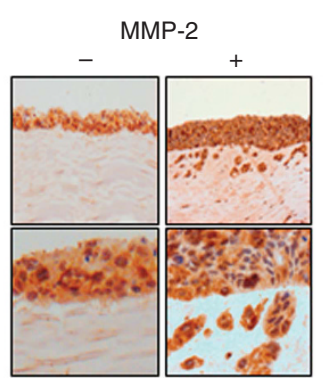

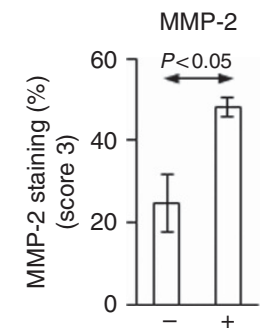

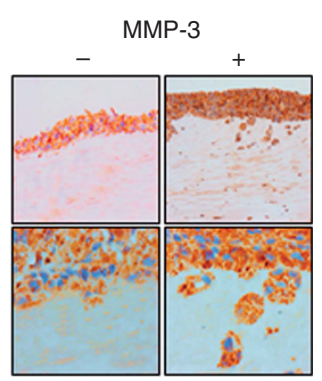

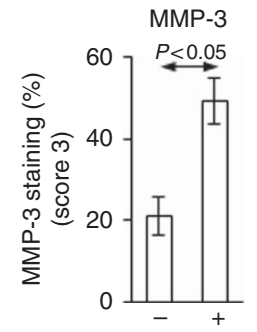

C
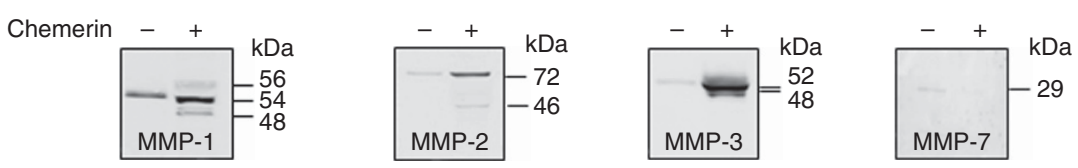

D

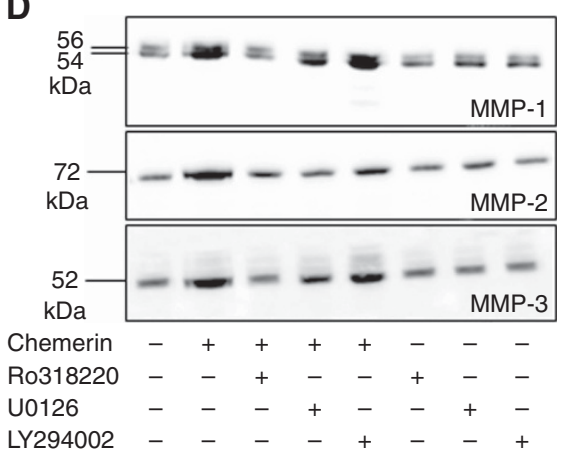

E

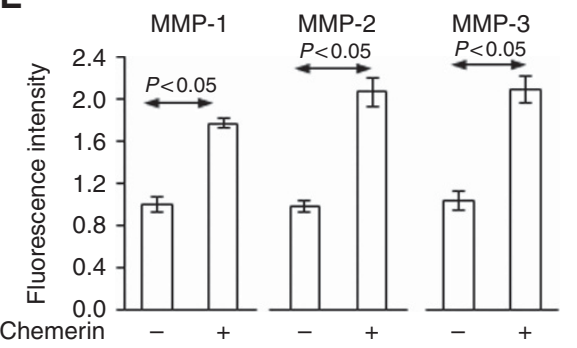

Figure 5. Chemerin increases MMP-1, MMP-2 and MMP-3 expression and activity. (A) MMP-1, MMP-2 and MMP-3 staining in organotypic cultures of OE21 cells and CAMs. (B) Quantification of MMP-1, MMP-2 and MMP-3 expression in organotypic cultures of OE21 cells and CAMs. Horizontal arrows, $P<0.05$, t-test. (C) Western blots demonstrating increased MMP-1, MMP-2 and MMP-3 expression by chemerin in OE21 cells. (D) Western blots showing the effect of Ro318220, U0126 and LY294002 on chemerin-stimulated MMP-1, MMP-2 and MMP-3 expression. (E) Fluorescence activity assays demonstrate increased MMP-1, MMP-2 and MMP-3 enzyme activities with chemerin. Horizontal arrows, $P<0.05$, t-test.

ChemR23, is expressed by OSC cells; moreover, chemerin stimulates migration, invasion and proliferation of these cells by a pathway sensitive to the ChemR23 antagonist CCX832. The data further show that CAMs have enhanced capacity for stimulation of OE21 cell invasion, via chemerin, and that these effects are mediated in part by chemerin via induction of MMPs. Collectively, the data raise the prospect that inhibition of ChemR23 may help delay progression in OSC.

In addition to increased expression in cancer-derived myofibroblasts, chemerin is also expressed by epithelial cells in the developing intestine (Maheshwari et al, 2009) and at the sites of inflammation in the alimentary tract (Dranse et al, 2015). In models of intestinal inflammation using ChemR23 null and w/t mice, there is a delayed progression with evidence for a local rather than systemic role of chemerin (Dranse et al, 2015). Previous studies have suggested that chemerin might contribute to the recruitment of dendritic cells in Barrett's oesophagus that promote a tolerogenic environment (Somja et al, 2013). However, aside from an involvement in immune mechanisms, it also appears that chemerin may directly influence cancer cell invasion. In gastric cancer AGS cells, there is evidence that chemerin contributes to invasion in part via MMP-7 (Wang et al, 2014); however, these effects seem to be mediated by an alternative receptor, GPR1 (Rourke et al, 2015). The present data show that in OSC, increased expression of chemerin in cancer myofibroblasts leads to invasion of cancer cells, but in this case mediated by ChemR23 and amenable to inhibition by ChemR23 antagonists. The data therefore add novel dimensions to the recognised property of stromal cells in accelerating tumour invasion.

In organotypic cultures, OE21 cells have been shown to exhibit an invasive phenotype resembling that of primary tumours (Underwood et al, 2010). The capacity of ATMs or NTMs to promote cancer cell invasion is relatively modest, but a strong effect is obtained with CAMs. By comparison, gel contractionwhich is a defining property of myofibroblasts-did not differ between CAMs, ATMs and NTMs. The invasion response is accompanied by the expression of multiple MMPs including MMP-1, MMP-2 and MMP-3, both in cancer cells and in 
myofibroblasts, and at least for MMP-1 and MMP-3 this resembles the pattern of expression in OSC in vivo. Increased expression of MMP-1, MMP-2 and MMP-3 in response to chemerin is mediated by PKC and MAP kinase, and in the case of MMP-1 is thought to act via the PEA3 transcription factor family (Keld et al, 2010).

Multiple extracellular proteases are likely to be involved in the invasion response to chemerin. It has been known for some time that MMP-1 expression in oesophageal cancer is associated with poor outcome (Murray et al, 1998; Groblewska et al, 2012; Tao et al, 2012). The potential role of chemerin in driving expression of MMP-1 and other MMPs in these cells is consistent with a larger body of evidence showing, for example, that chemerin stimulates MMP-2 expression in MSCs (Kumar et al, 2014), and MMP-2 and MMP-9 expression in endothelial cells (Kaur et al, 2010). The latter are implicated in angiogenic responses that may enhance the tumourigenic effects in vivo. Even so, the present data show that chemerin may mediate the interaction of just two classes of cells, myofibroblast and cancer cells, to promote an aggressive phenotype.

The outcome for OSC remains dismal not least because diagnosis is made relatively late. In addition to issues around early detection, an understanding of what promotes the early progression of the disease is likely to help in the development of novel therapeutic strategies. The present findings build on the general idea (Kalluri and Zeisberg, 2006; De Wever et al, 2014) that stromal cells, and specifically modified myofibroblasts, promote cancer invasion by showing that these effects may be mediated, at least in part, via chemerin acting at the ChemR23 receptor. In the case of OSC, other mechanisms are likely to be involved, as a variety of strategies directed at inhibiting chemerin/ChemR23 interactions (immunoneutralisation, siRNA and receptor antagonists) did not fully suppress the effects of myofibroblasts; these may include both other mediators and possibly chemerin action at other receptors, for example, GPR1. Further work is clearly needed in this area. The importance of chemerin/ChemR23 interactions, however, lies in the fact that in several different models these are clearly a component in the myofibroblast effects on cancer cells and, crucially, antagonists at ChemR23, including CCX832, have now been characterised. The findings therefore raise the prospect of new therapeutic approaches directed at limiting the invasion of this cancer.

\section{ACKNOWLEDGEMENTS}

We are grateful to ChemoCentryx (Mountain View, CA, USA) for a generous gift of CCX832 and CCX826. This work was supported by North West Cancer Research and Wellcome Trust.

\section{CONFLICT OF INTEREST}

The authors declare no conflict of interest.

\section{REFERENCES}

Balabanova S, Holmberg C, Steele I, Ebrahimi B, Rainbow L, Burdyga T, McCaig C, Tiszlavicz L, Lertkowit N, Giger OT, Oliver S, Prior I, Dimaline R, Simpson D, Beynon R, Hegyi P, Wang TC, Dockray GJ, Varro A (2014) The neuroendocrine phenotype of gastric myofibroblasts and its loss with cancer progression. Carcinogenesis 35: 1798-1806.

De Wever O, Demetter P, Mareel M, Bracke M (2008) Stromal myofibroblasts are drivers of invasive cancer growth. Int J Cancer 123: 2229-2238.

De Wever O, Van Bockstal M, Mareel M, Hendrix A, Bracke M (2014) Carcinoma-associated fibroblasts provide operational flexibility in metastasis. Semin Cancer Biol 25: 33-46.
Dranse HJ, Rourke JL, Stadnyk AW, Sinal CJ (2015) Local chemerin levels are positively associated with DSS-induced colitis but constitutive loss of CMKLR1 does not protect against development of colitis. Physiol Rep 3: e12497.

Groblewska M, Siewko M, Mroczko B, Szmitkowski M (2012) The role of matrix metalloproteinases (MMPs) and their inhibitors (TIMPs) in the development of esophageal cancer. Folia Histochem Cytobiol 50: 12-19.

Grugan KD, Miller CG, Yao Y, Michaylira CZ, Ohashi S, Klein-Szanto AJ, Diehl JA, Herlyn M, Han M, Nakagawa H, Rustgi AK (2010) Fibroblast-secreted hepatocyte growth factor plays a functional role in esophageal squamous cell carcinoma invasion. Proc Natl Acad Sci USA 107: 11026-11031.

Hanahan D, Weinberg RA (2011) Hallmarks of cancer: the next generation. Cell 144: 646-674.

Holmberg C, Ghesquiere B, Impens F, Gevaert K, Kumar JD, Cash N, Kandola S, Hegyi P, Wang TC, Dockray GJ, Varro A (2013) Mapping proteolytic processing in the secretome of gastric cancer-associated myofibroblasts reveals activation of MMP-1, MMP-2, and MMP-3. J Proteome Res 12: 3413-3422.

Holmberg C, Quante M, Steele I, Kumar J, Balabanova S, Duval C, Czepan M, Rakonczayjr Z, Tiszlavicz L, Nemeth I, Lazar G, Simonka Z, Jenkins R, Hegyi P, Wang T, Dockray G, Varro A (2012a) Release of TGFbetaig-h3 by gastric myofibroblasts slows tumor growth and is decreased with cancer progression. Carcinogenesis 33: 1553-1562.

Holmberg C, Quante M, Steele I, Kumar JD, Balabanova S, Duval C, Czepan M, Rakonczay Jr. Z, Tiszlavicz L, Nemeth I, Lazar G, Simonka Z, Jenkins R, Hegyi P, Wang TC, Dockray GJ, Varro A (2012b) Release of TGFbetaig-h3 by gastric myofibroblasts slows tumor growth and is decreased with cancer progression. Carcinogenesis 33: 1553-1562.

Jemal A, Bray F, Center MM, Ferlay J, Ward E, Forman D (2011) Global cancer statistics. CA Cancer J Clin 61: 69-90.

Jiang L, Gonda TA, Gamble MV, Salas M, Seshan V, Tu S, Twaddell WS, Hegyi P, Lazar G, Steele I, Varro A, Wang TC, Tycko B (2008) Global hypomethylation of genomic DNA in cancer-associated myofibroblasts. Cancer Res 68: 9900-9908.

Kalluri R, Zeisberg M (2006) Fibroblasts in cancer. Nat Rev Cancer 6: 392-401.

Kaur J, Adya R, Tan BK, Chen J, Randeva HS (2010) Identification of chemerin receptor (ChemR23) in human endothelial cells: chemerininduced endothelial angiogenesis. Biochem Biophys Res Commun 391: $1762-1768$.

Keld R, Guo B, Downey P, Gulmann C, Ang YS, Sharrocks AD (2010) The ERK MAP kinase-PEA3/ETV4-MMP-1 axis is operative in oesophageal adenocarcinoma. Mol Cancer 9: 313.

Kumar JD, Holmberg C, Balabanova S, Borysova L, Burdyga T, Beynon R, Dockray GJ, Varro A (2015a) Mesenchymal stem cells exhibit regulated exocytosis in response to chemerin and IGF. PloS ONE 10: e0141331.

Kumar JD, Holmberg C, Kandola S, Steele I, Hegyi P, Tiszlavicz L, Jenkins R, Beynon RJ, Peeney D, Giger OT, Alqahtani A, Wang TC, Charvat TT, Penfold M, Dockray GJ, Varro A (2014) Increased expression of chemerin in squamous esophageal cancer myofibroblasts and role in recruitment of mesenchymal stromal cells. PloS ONE 9: e104877.

Kumar JD, Steele I, Moore AR, Murugesan SV, Rakonczay Z, Venglovecz V, Pritchard DM, Dimaline R, Tiszlavicz L, Varro A, Dockray GJ (2015b) Gastrin stimulates MMP-1 expression in gastric epithelial cells: putative role in gastric epithelial cell migration. Am J Physiol Gastrointest Liver Physiol 309: G78-G86.

Maheshwari A, Kurundkar AR, Shaik SS, Kelly DR, Hartman Y, Zhang W, Dimmitt R, Saeed S, Randolph DA, Aprahamian C, Datta G, Ohls RK (2009) Epithelial cells in fetal intestine produce chemerin to recruit macrophages. Am J Physiol Gastrointest Liver Physiol 297: G1-G10.

Meder W, Wendland M, Busmann A, Kutzleb C, Spodsberg N, John H, Richter R, Schleuder D, Meyer M, Forssmann WG (2003) Characterization of human circulating TIG2 as a ligand for the orphan receptor ChemR23. FEBS Lett 555: 495-499.

Murray GI, Duncan ME, O’Neil P, McKay JA, Melvin WT, Fothergill JE (1998) Matrix metalloproteinase-1 is associated with poor prognosis in oesophageal cancer. J Pathol 185: 256-261.

Ngo P, Ramalingam P, Phillips JA, Furuta GT (2006) Collagen gel contraction assay. Methods Mol Biol 341: 103-109.

Nystrom ML, Thomas GJ, Stone M, Mackenzie IC, Hart IR, Marshall JF (2005) Development of a quantitative method to analyse tumour cell invasion in organotypic culture. J Pathol 205: 468-475. 
Ohlund D, Elyada E, Tuveson D (2014) Fibroblast heterogeneity in the cancer wound. J Exp Med 211: 1503-1523.

Orimo A, Gupta PB, Sgroi DC, renzana-Seisdedos F, Delaunay T, Naeem R, Carey VJ, Richardson AL, Weinberg RA (2005) Stromal fibroblasts present in invasive human breast carcinomas promote tumor growth and angiogenesis through elevated SDF-1/CXCL12 secretion. Cell 121: 335-348.

Pennathur A, Gibson MK, Jobe BA, Luketich JD (2013) Oesophageal carcinoma. Lancet 381: 400-412.

Quail DF, Joyce JA (2013) Microenvironmental regulation of tumor progression and metastasis. Nat Med 19: 1423-1437.

Reid BJ, Li X, Galipeau PC, Vaughan TL (2010) Barrett's oesophagus and oesophageal adenocarcinoma: time for a new synthesis. Nat Rev Cancer 10: $87-101$.

Rourke JL, Dranse HJ, Sinal CJ (2015) CMKLR1 and GPR1 mediate chemerin signaling through the RhoA/ROCK pathway. Mol Cell Endocrinol 417: $36-51$.

Smola H, Thiekotter G, Fusenig NE (1993) Mutual induction of growth factor gene expression by epidermal-dermal cell interaction. J Cell Biol 122: $417-429$.

Somja J, Demoulin S, Roncarati P, Herfs M, Bletard N, Delvenne P, Hubert P (2013) Dendritic cells in Barrett's esophagus carcinogenesis: an inadequate microenvironment for antitumor immunity? Am J Pathol 182: $2168-2179$.
Tao YS, Ma XY, Chai DM, Ma L, Feng ZZ, Cheng ZN, Lai MD (2012) Overexpression of MMP-1 and VEGF-C is associated with a less favorable prognosis in esophageal squamous cell carcinoma. Onkologie 35: 651-656.

Underwood TJ, Derouet MF, White MJ, Noble F, Moutasim KA, Smith E, Drew PA, Thomas GJ, Primrose JN, Blaydes JP (2010) A comparison of primary oesophageal squamous epithelial cells with HET-1A in organotypic culture. Biol Cell 102: 635-644.

Wang C, Wu WK, Liu X, To KF, Chen GG, Yu J, Ng EK (2014) Increased serum chemerin level promotes cellular invasiveness in gastric cancer: a clinical and experimental study. Peptides 51: 131-138.

Wang D, DuBois RN (2015) Immunosuppression associated with chronic inflammation in the tumor microenvironment. Carcinogenesis 36: 1085-1093.

Wittamer V, Franssen JD, Vulcano M, Mirjolet JF, Le Poul E, Migeotte I, Brezillon S, Tyldesley R, Blanpain C, Detheux M, Mantovani A, Sozzani S, Vassart G, Parmentier M, Communi D (2003) Specific recruitment of antigen-presenting cells by chemerin, a novel processed ligand from human inflammatory fluids. J Exp Med 198: 977-985.

This work is published under the standard license to publish agreement. After 12 months the work will become freely available and the license terms will switch to a Creative Commons AttributionNonCommercial-Share Alike 4.0 Unported License. 